Tohoku J. exp. Med., 1972, 107, 359-365

\title{
Heavy-density Particles of Australia Antigen Detected in a Human Plasma Pool
}

\author{
Ryoichi Shirachi, Noriyoshi Sukeno, Takusei Umenai \\ and NaKao Ishida \\ Department of Bacteriology, Tohoku University School of Medicine \\ and Miyagi Prefectural Institute of Public Health, Sendai
}

\begin{abstract}
Shirachi, R., Sukgno, N., Umenai, T. and Ishida, N. Heavy-density Particles of Australia Antigen Detected in a Human Plasma Pool. Tohoku J. exp. Med., 1972, 107 (4), 359-365__ Biophysical study of Australia antigen (Au) was made with 5 specimens including 3 plasmas and 2 plasma pools which had been known to be Au carriers. A fraction which could be detected both by complement fixation test and by Ouchterlony double diffusion test was obtained with all of the specimens and this could be banded at a buoyant density of 1.21-1.23 $\mathrm{g} / \mathrm{cm}^{3}$ in $\mathrm{CsCl}$. In addition, another fraction with a buoyant density of $1.28 \mathrm{~g} /$ $\mathrm{cm}^{3}$ was recovered from one of the plasma pools. This fraction was detected, however, only by complement fixation test. Electron microscopic study of the latter fraction revealed small particles about $3-4 \mathrm{~m} \mu$ in diameter, suggesting subunits of known Au antigen particles.—__ hepatitis; Au antigen
\end{abstract}

In 1968, Bayer, Blumberg and Werner described $20 \mathrm{~m} \mu$ particles in Australia $\mathrm{Au}$ ) antigen-containing serum fraction from sucrose gradients. The particles were virus-like and aggregated by the same sera that precipitated the antigen. On the basis of such observations, many investigators have been convinced that the antigen is intimately associated with a virus-like structure that is responsible for B type hepatitis (Prince 1968, Blumberg et al. 1968). When studies were undertaken to determine the densities of the $\mathrm{Au}$ antigen and the particle morphology with various plasma specimens collected throughout Japan, one plasma pool obtained from Tokyo University through the courtesy of Dr. Okochi contained two antigen fractions of different densities. This report describes characteristics of these two antigens, which bear on the subunit structure of the known $\mathrm{Au}$ particles.

\section{Materials and Methods}

Source of $A u$ antigen

Five plasma specimens were purified under the same condition. Three plasmas (B, H, C) collected through Japan Red Cross Blood Center of Sendai were from healthy carriers of $\mathrm{Au}$ antigen. Two plasma pools $(\mathrm{K}, \mathrm{P})$ were obtained from Tokyo University. The pool $\mathrm{K}$ was made from two individuals (5210 and 1008), and $\mathrm{P}$ from three $(2129,2290$ and 0128). They were stored frozen at $-20^{\circ} \mathrm{C}$ until use.

Received for publication, January 18, 1972. 
Complement fixation $(C F)$ test

The CF antigen titers were measured in microtiter plates, using 2 CF antibody units and 2 exact units of complement (Sever, 1962). Serum containing antibody to Au was obtained from a healthy high school boy (Chubachi) and was heated at $56^{\circ} \mathrm{C}$ for $30 \mathrm{~min}$. This serum has been used as a reference antibody for these 2 years. Gradient fractions of $\mathrm{Au}$ antigen were tested with prior heat inactivation.

Ouchterlony doulbe diffusion (AGD) and immunoelectrosyneresis (IES) tests

The micro-Ouchterlony technique was earried out with the use of $1 \%$ agar-agar (Wako Pure Chemicals) and $0.01 \mathrm{M}$ veronal buffer ( $\mathrm{pH} \mathrm{8.6)} \mathrm{system.} \mathrm{Au} \mathrm{antiserum} \mathrm{was} \mathrm{added} \mathrm{in}$ the center well of seven hole micro-Ouchterlony pattern (LKB) on slide and samples containing Au antigen were added in the peripheral wells. The slides were kept for 48 hrs at room temperature in a moist chamber. The IES test of sample $(5 \mu l)$ was performed

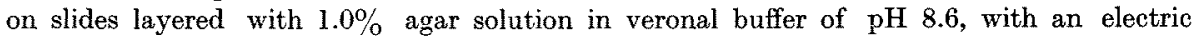
strength of $15 \mathrm{~V} / \mathrm{cm}$ for $40 \mathrm{~min}$ at room temperature.

\section{Reagents}

Cesium chloride (Merck AG) was used without further purification. Sucrose solutions were prepared by dissolving ribonuclease free sucrose (Nakarai Chem.) in $0.01 \mathrm{M}$ phosphate buffer ( $\mathrm{pH}$ 7.4) with gentle mixing.

\section{Pretreatment of serum before 2-step purification}

Two tenth $\mathrm{ml}$ of $1 \mathrm{M} \mathrm{CaCl}_{2}$ solution was added to $20 \mathrm{ml}$ of plasma or plasma pool for the removal of fibrinogen. This was left at room temperature for $3 \mathrm{hrs}$ and stood at $4^{\circ} \mathrm{C}$ overnight. After light centrifugation, fibrin clot was removed. For further purification, defibrinated plasmas were diluted 3 times with 0.0I M phosphate buffered saline of $\mathrm{pH}$ 7.2 (PBS).

First-step rate zonal centrifugation on sucrose gradient

All centrifugation steps were performed in a Hitachi model 65P centrifuge. $20 \mathrm{ml}$ of diluted serum were layered on a preformed $10 \mathrm{ml}$ discontinuous 40 and $60 \%(\mathrm{w} / \mathrm{w})$ sucrose gradient and centrifuged at $68,000 \times \mathrm{g}$ for $15 \mathrm{hrs}$ at $5^{\circ} \mathrm{C}$. Fractions of $0.5 \mathrm{ml}$ were collected from the bottom of the centrifuge tube. CF titer in each fraction shown in Fig. 1 is the reciprocal of the antigen dilution.

Second-step isopycnic banding in $\mathrm{CsCl}$ density gradient

A $3.5 \mathrm{ml}$ sample was layered on a $1.5 \mathrm{ml}$ discontinuous 1.1 to $1.5 \mathrm{~g} / \mathrm{cm}^{3} \mathrm{CsCl}$ gradient and run at $68,000 \times \mathrm{g}$ for $20 \mathrm{hrs}$ at $5^{\circ} \mathrm{C}$.

\section{Density determination}

The density of individual fractions was determined from curves relating refractive index to density. Refractive indexes were read at $20^{\circ} \mathrm{C}$ with an Abbe $3 \mathrm{~L}$ type refractometer.

\section{Electron microscopy}

Preparations of purified Au antigen were examined in a Hitachi HU-11 B electron microscope at an instrumental magnification of $40,000 \times$. The preparation was placed on a carbon-coated collodion-covered grid and stained with $2 \%$ phosphotungustic acid at $\mathrm{pH}$ 7.2 . 


\section{Results}

\section{Preparation of partially purified Au antigen}

Five $\mathrm{Au}$ positive specimens obtained from different sources were subjected to the same two-step purification procedure to prepare concentrated and partially purified antigen.

First step purification was a centrifugation at $68,000 \times \mathrm{g}$ for $16 \mathrm{hrs}$ on a discontinuous gradient of sucrose $(7 \mathrm{ml}$ of $40 \%$ and $3 \mathrm{ml}$ of $60 \%$ ). Almost all of the antigenicity was concentrated in $40 \%$ sucrose fraction as illustrated in Fig. 1. A visible turbid band was observed at this fraction.

The recovery rate was almost $100 \%$ with all of the 5 specimens. The second step isopycnic banding made on preformed discontinuous $\mathrm{CsCl}$ gradients $(\rho=1.1$, 1.3 and 1.5) at $68,000 \times \mathrm{g}$ for $20 \mathrm{hrs}$ resulted in the high condensation of antigen in $\rho=1.3$ fraction (Fig. 1). Again the same recovery rate of almost $80 \%$ was obtained with 5 specimens.

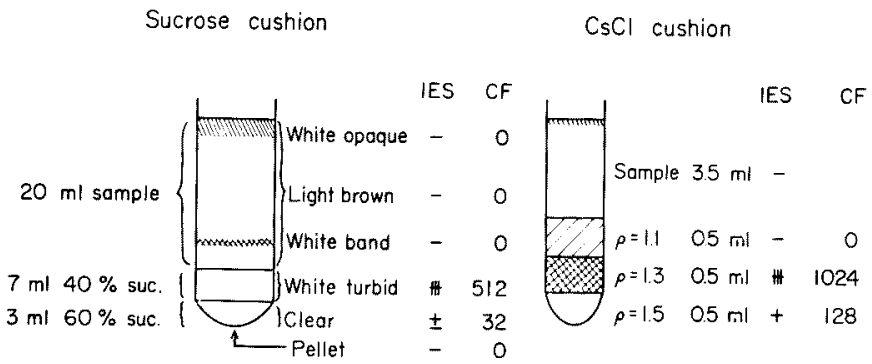

Fig. 1. Centrifugation profile of Au antigen in two step purification process.

Three times diluted, defibrinated plasma specimens were used as the starting material. First sucrose cushion centrifugation was at $68,000 \times \mathrm{g}$ for $16 \mathrm{hrs}$. Second step centrifugation was made on preformed discontinuous $\mathrm{CsCl}$ gradients at $68,000 \times \mathrm{g}$ for 20 hrs. All fractions were collected by the bottom-drip method and tested for antigenicity by IES and CFT.

\section{Isopycnic banding of Au antigen in $\mathrm{CsCl}$ density gradients}

Partially purified Au antigens obtained from 5 different sources described above were finally isopycnically banded by using continuous density gradients of $\mathrm{CsCl}$, at $158,000 \times \mathrm{g}$ for $48 \mathrm{hrs}$. For this $0.5 \mathrm{ml}$ sample containing $81,920 \mathrm{CF}$ titer $/ \mathrm{ml}$ was mixed with $4.5 \mathrm{ml}$ of $\mathrm{CsCl}$ in water with final density of $1.26 \mathrm{~g} / \mathrm{cm}^{3}$. Gradient fractions of Au antigen were tested with CF, AGD and IES tests. Before tests, all fractions were dialyzed against PBS for $24 \mathrm{hrs}$ for 5 times.

Obtained results with plasma $H$ was illustrated in Fig. 2-a and with the plasma pool $\mathrm{P}$, in Fig. 2-b. With the rest of the sera $\mathrm{B}$ and $\mathrm{C}$ and the plasma pool $\mathrm{K}$, almost identical result as that of $\mathrm{H}$, shown in Fig. 2-a, was obtained.

In Fig. 2-a, Au was sedimented as a discrete zone of CF activity at a density of $1.21-1.23 \mathrm{~g} / \mathrm{cm}^{3}$. In AGD or IES test, almost parallel results were obtained 


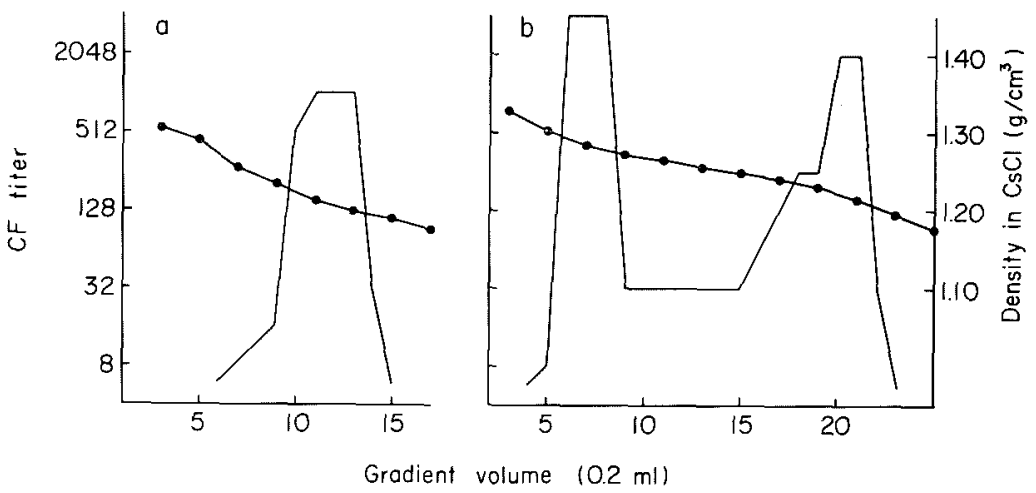

Fig. 2. Isopycnic banding of $\mathrm{Au}$ in continuous $\mathrm{CsCl}$ density gradient.

A $0.5 \mathrm{ml}$ sample of partially purified $\mathrm{Au}$ antigen was layered on a $4.5 \mathrm{ml}$ continuous $1.26 \mathrm{~g} / \mathrm{cm}^{3} \mathrm{CsCl}$ gradient and run at $158,000 \times \mathrm{g}$ for $48 \mathrm{hrs}$ at $5 \mathrm{C}$. Fractions of 0.2 $\mathrm{ml}$ were collected from the bottom of the centrifuge tube.

as those of CF test. In two out of the four specimens mentioned above, a shoulder was found at a heavier fraction, which was not clearly resolved from the main peak, whereas with the plasma pool $P$, two discrete peaks appeared as shown in Fig. 2-b. The CF activity distribution at a density of $1.21 \mathrm{~g} / \mathrm{cm}^{3}$ was not different from that obtained with the rest four specimens, and the AGD and IES activity paralleled to the CF titer distribution, whereas another high titer peak in CF test was recovered in a sharp zone at a density of $1.28 \mathrm{~g} / \mathrm{cm}^{3}$. Nevertheless, any activity was not found in AGD and IES with this fraction.

\section{Electron micrographic study of the high-density $C F$ antigen}

High-density antigen fraction obtained from the pool $\mathrm{P}$, and low-density fractions obtained from different sources were examined under electron microscope. Fig. 3 illustrates the negatively stained $\mathrm{Au}$ particles found in low-density fraction of specimen $H$. The particles revealed fairly large deviation in size but had a modal diameter of $22 \mathrm{~m} \mu$. Surface structures were apparent on some particles and there was a suggestive evidence of symmetric arrangements. These particles are similar in morphology to the particles so far described as Au antigen particles (Barker et al. 1969, Gerin et al. 1969). Tubular forms described by Bayer et al. (1968) and Almeida et al. (1969) were also found in this low-density fractions originated from 5 specimens, although the relative concentration to cubic particles is different from specimen to specimen. Dane's large particles (Dane et al. 1970, Jokelainen et al. 1970) were predominantly encountered at a density of $1.24 \mathrm{~g} / \mathrm{cm}^{3}$ in 2 specimens out of 5 .

In high-density antigen peak of the specimen $\mathbf{P}$, no cubic, tubular and Dane's particles were found. Particles revealed in this fraction were fairly small particulates but uniform in their morphology. Average diameter was estimated to be between 3 and $4 \mathrm{~m} \mu$ (Fig. 4). Their arrangement in negatively stained pre- 


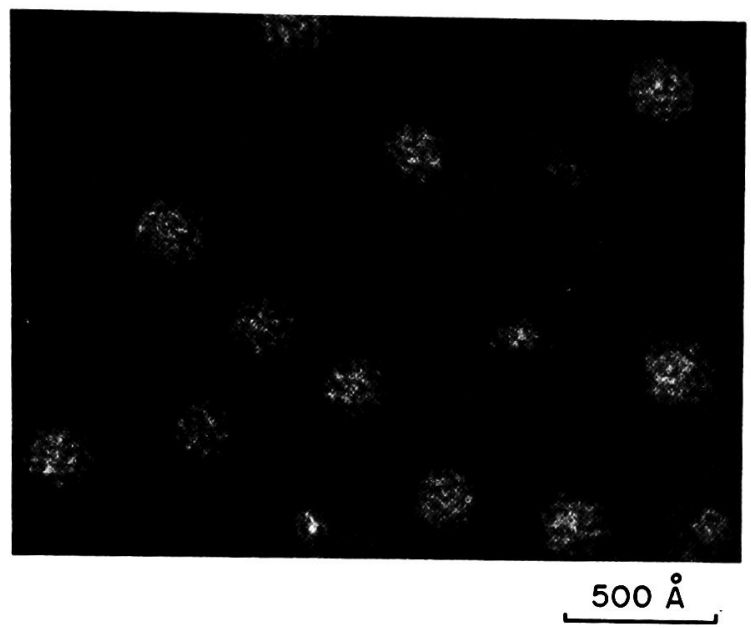

Fig. 3. Electron micrograph of low-density Au particles.

Partially purified $\mathrm{Au}$ antigen were examined in a Hitachi HU-11B electron microscope at an instrumental magnification of 40,000 (photographic enlargement $\times 174,000$ ).

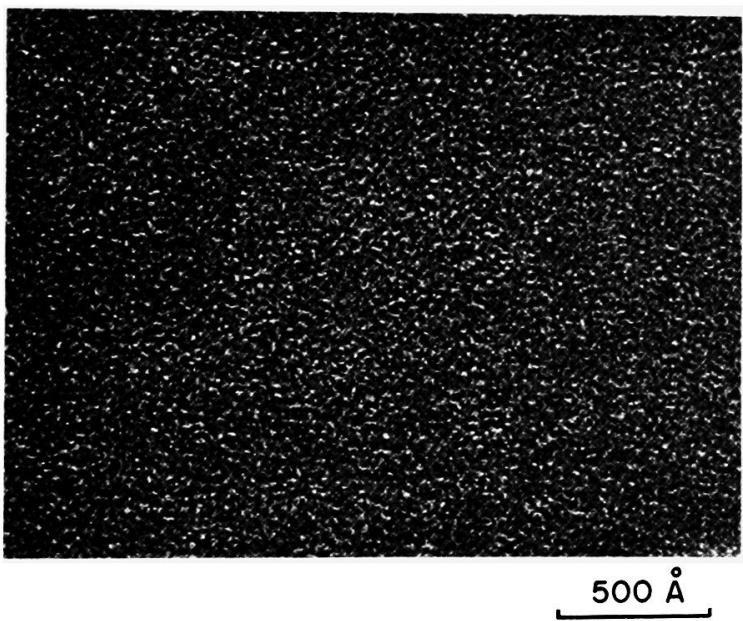

Fig. 4. Electron micrograph of heavy-density small particulates $(\rho=1.28)$. Photographic magnification of 17,4000 .

paration was fairly regular in a sense that many dimers, tetramers or polymers were found.

\section{Discussion}

To obtain the partially purified Au antigens with high recovery rate, a simplified two-step purification procedure was proposed in this article. First-step sucrose 
cushion centrifugation resulted in a condensation of antigen in $40 \%$ sucrose layer. By this means, Au antigens in $20 \mathrm{ml}$ serum were concentrated into $5 \mathrm{ml}$ solution and this was subjected to the second-step isopycnic banding in $\mathrm{CsCl}$ cushion. Through this second step, antigens can be concentrated into $0.5 \mathrm{ml}$ with high recovery rate. Electron microscopic study of this fraction revealed the homogenous distribution of virus-like particles of $22 \mathrm{~m} \mu$ size. However, a trace amount of albumin could not be removed from this fraction, when examined by means of immunoelectrophoresis against rabbit anti-human serum antibody.

When these partially purified antigens are subjected to the final purification process of isopycnic banding in continuous gradient concentration of $\mathrm{CsCl}$ (Barker et al. 1969, Millman et al. 1970, Gerin et al. 1971), two peaks were encountered with the plasma pool P. The second high-density fraction could not be detected with the rest 4 specimens, and in our recent experience of 10 purification trials through the year 1971, only one out of 10 revealed such two peaks. This highdensity fraction seems to be identical with the second population of CF activity described by Gerin et al. (1968). However, they found this activity in higher density than ours, i.e. 1.35 to $1.40 \mathrm{~g} / \mathrm{cm}^{3}$. In their description, they encountered this second peak with frozen and thawed preparation as well as after the treatment of $1.20 \mathrm{~g} / \mathrm{cm}^{3}$ fraction with Tween 80 . However, their description did not extend to the electron microscopic examination of this high-density antigen. Our study clearly illustrates that the antigenicity in this second peak can be detected only by means of CF test, but not by AGD and IES tests.

Furthermore, known antigenic particles such as virus-like cubic, tubular and large particles could not be found in this fraction. Homogenous distribution of small cubic elementary particles of $3-4 \mathrm{~m} \mu$ in diameter was encountered. When the concentration of these elementary particles was high in negatively stained preparation, they showed the tendency of lattice arrangements. Many tetramers and dimers were found. This observation is tempting to speculate that this highdensity fraction is a particulate population of protein which has been released in some manner from low-density component of Au antigen. The density of 1.28 $\mathrm{g} / \mathrm{cm}^{3}$ just fits the described density of a simple protein.

\section{Acknowledģments}

This work was supported by research grants from the Ministry of Education and the Ministry of Welfare. We are indebted to Dr. J. Yamaguchi, Research Institute of Tuberculosis, Leprosy and Cancer and Dr. K. Yada and Dr. S. Takahashi, Research Institute for Scientific Measurements, Tohoku University, for their assistance in the electron microscopy.

\section{References}

1) Almeida, J.D. \& Waterson, A.P. (1969) Immune complexes in hepatitis. Lancet, 2, 983-986.

2) Barker, L.F., Smith, K.O., Gehle, W.D. \& Shulman, N.R. (1969) Some antigenic and physical properties of virus-like particles in sera of hepatitis patients. $J$. Immunol, 102, 1529-1532. 
3) Bayer, M.E., Blumberg, B.S. \& Werner, B. (1968) Particles associated with Australia antigen in the sera of patients with leukaemia, Down's syndrome and hepatitis. Nature, 218, 1057-1059.

4) Blumberg, B.C., Sutnick, A.I. \& London, W.T. (1968) Hepatitis and leukemia; their relation to Australia antigen. Bull. N.Y. Acad. Med., 44, 1566-1586.

5) Dane, D.S. Cameron, C.H. \& Briggs, M. (1970) Virus-like particles in serum of patients with Australia-antigen-associated hepatitis. Lancet, 1, 695-698.

6) Gerin, J.L., Purcell, R.H., Hoggam, M.D., Holland, P.V. \& Chanock, R.M. (1969) Biophysical properties of Australia antigen. J. Virol., 4, 763-768.

7) Gerin, J.L., Holland, P.V. \& Purcell, R.H. (1971) Australia antigen: Largescale purification from human serum and biochemical studies of its proteins. $J$. Virol., 7, 569-576.

8) Jokelainen, P.T., Krohn, K., Prince, A.M. \& Finlayson, N.D.C. (1970) Electron microscopic observations on virus-like particles associated with $\mathrm{SH}$ antigen. $J$. Virol., 6, 685-689.

9) Millman, I., Loeb, L.A., Bayer, M.E. \& Blumberg, B.S. (1970) Australia antigen (a hepatitis-associated antigen). Purification and physical properties. J. exp. Med., 131, 1190-1199.

10) Prince, A.M. (1968) Au antigen detected in the blood during the incubation period of serum hepatitis. Proc. nat. Acad. Sci. (Wash.), 60, 814-821. 